
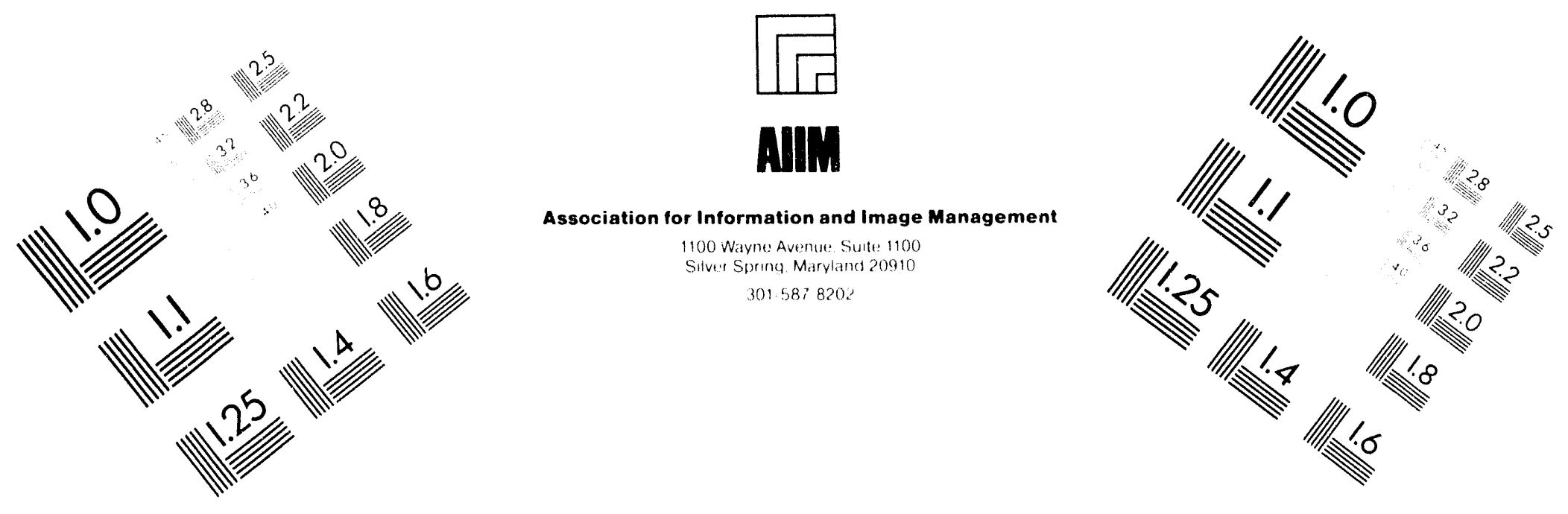

Centimeter

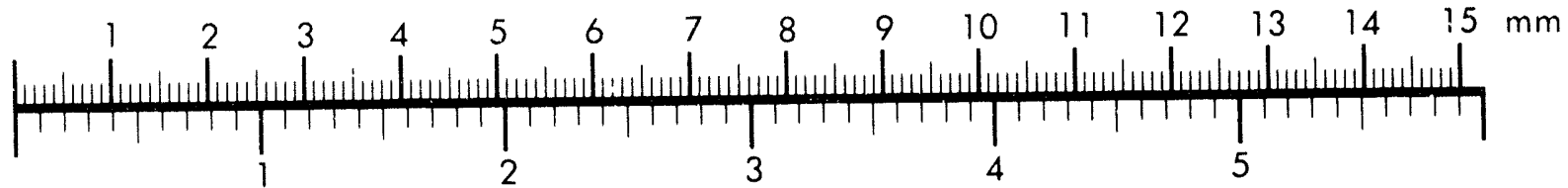

Inches
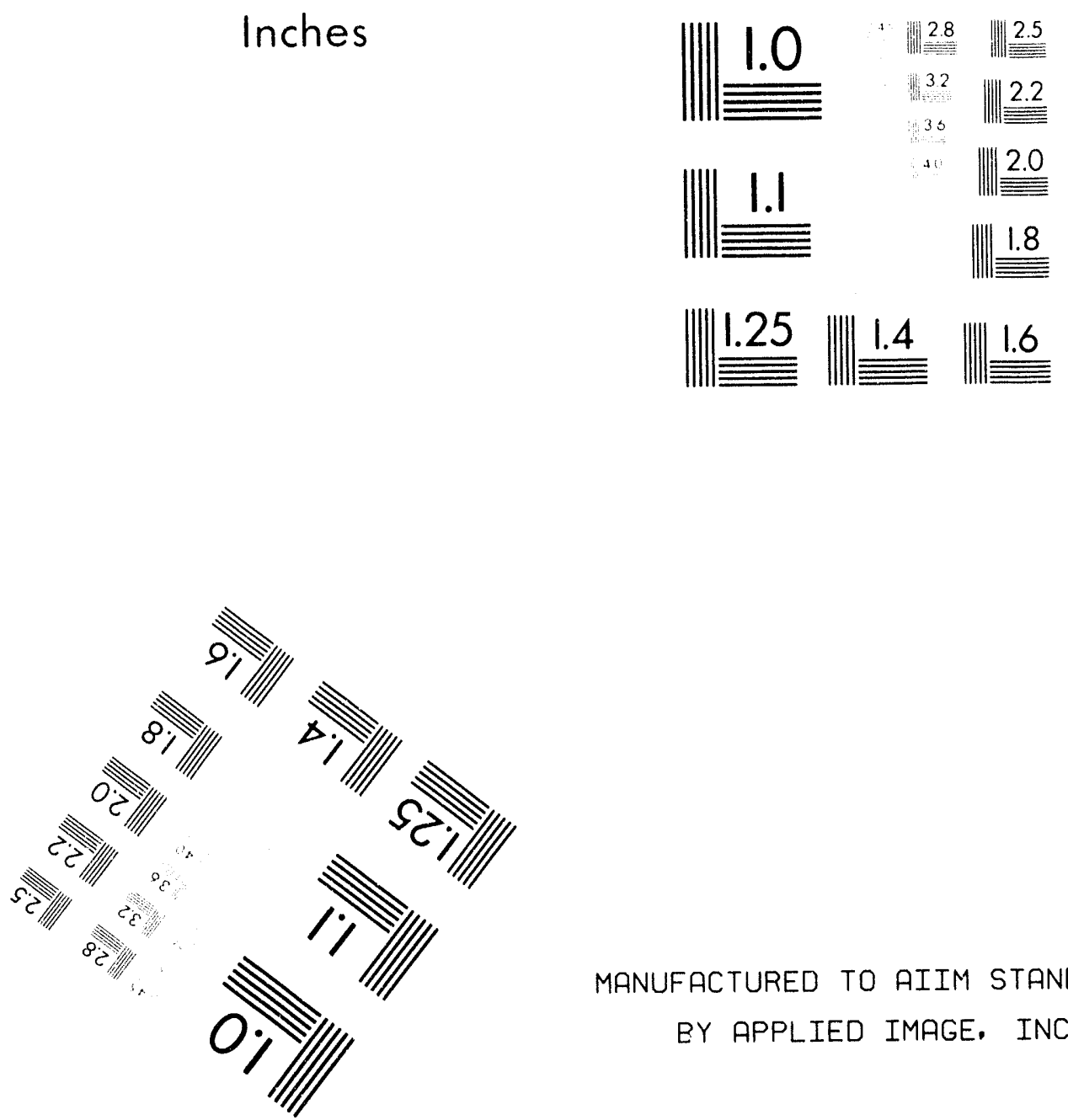

MANUFACTURED TO AIIM STANDARDS

BY APPLIED IMAGE, INC.

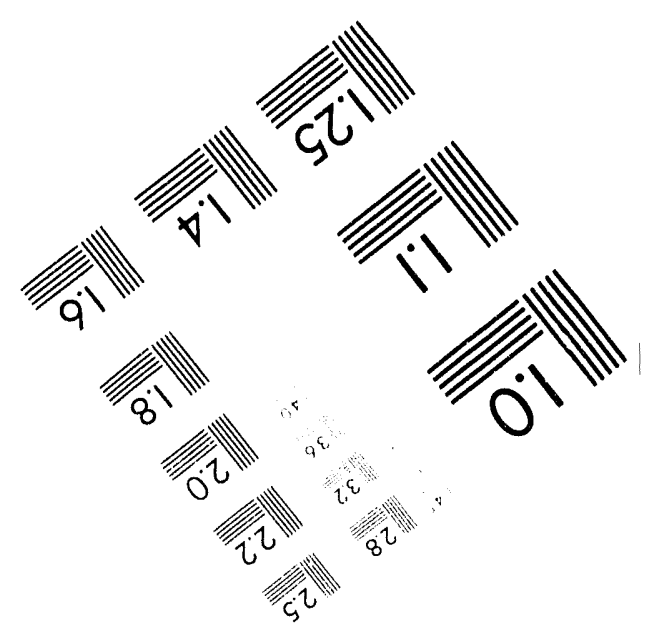



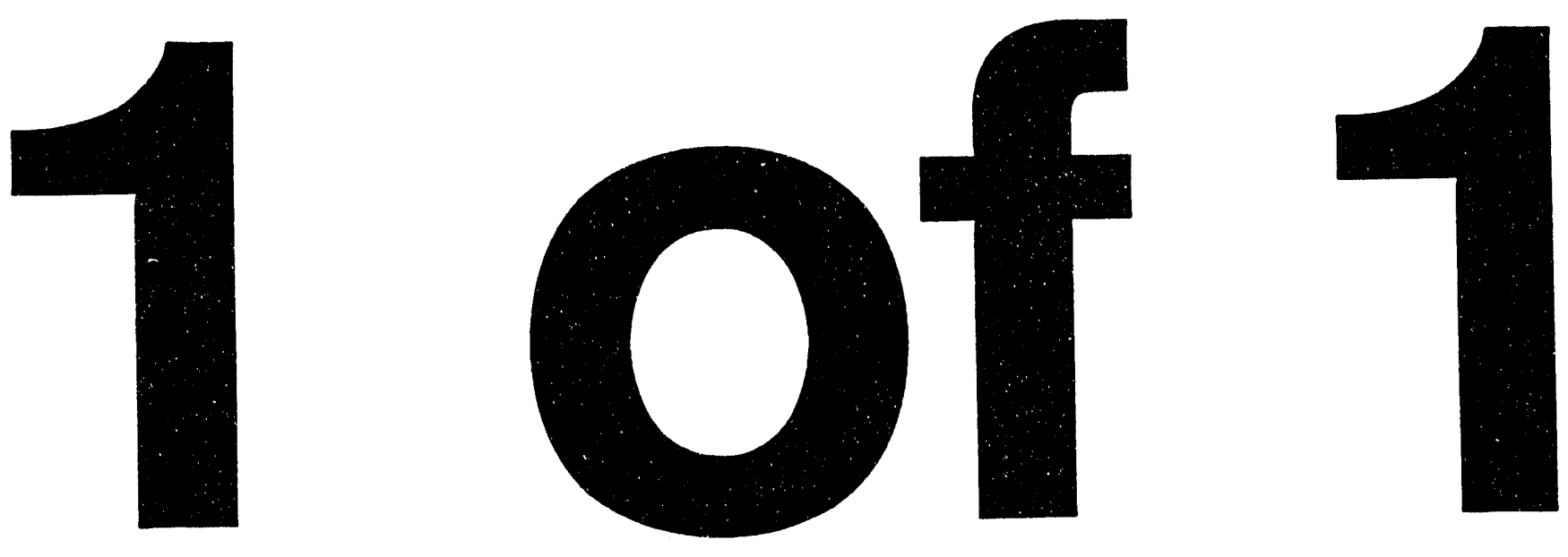


$$
\begin{aligned}
& \text { ANK/TD/CP-81425 } \\
& \text { Conf-940664--18 } \\
& \text { Paper }
\end{aligned}
$$

\section{COMPARISON OF LITHIUM AND THE EUTECTIC LEAD LITHIUM ALLOY, TWO CANDIDATE LIQUID METAL BREEDER MATERIALS FOR SELF-COOLED BLANKETS*}

by

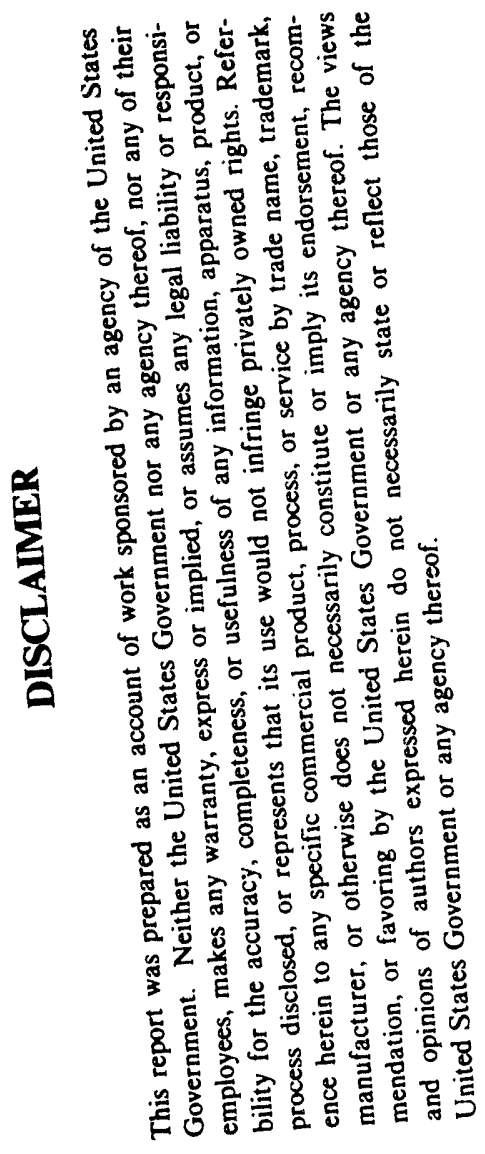

SIEGFRIED MALANG ${ }^{1}$ AND RICHARD F. MATTAS ${ }^{2}$

1Kernforschungszentrum Karlsruhe $\mathrm{GmbH}$, Postfach 3640, D76021, Karlsruhe, Germany

2Fusion Power Program

Technology Development Division

Argonne National Laboratory

Argonne, IL 60439 USA

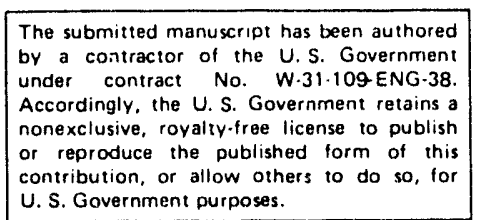

June 1994

Submitted to the Third International Symposium on Fusion Nuclear Technology, University of California at Los Angeles, June 27 - July 1, 1994.

* Work supported by the United States Department of Energy/Office of Fusion Energy, under Contract No. W-31-109-Eng-38 and by the European Union within the European Fusion Technology Program.

\section{RECEIVED}

JUL 149994

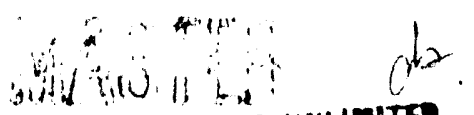

OP MisuTION OF THIS DOCUMENT IS UNLIMITE. 


\title{
COMPARISON OF LITHIUM AND THE EUTECTIC LEAD LITHIUM ALLOY, TWO CANDIDATE LIQUID METAL BREEDER MATERIALS FOR SELF-COOLED BLANKETS*
}

\author{
S. Malang1 and R. Mattas 2 \\ ${ }^{1}$ Kernforschungszentrum Karlsruhe GmbH, Postfach 3640, D76021, Karlsruhe, Germany \\ ${ }^{2}$ Argonne National Laboratory, 9700 South Cass Avenue, Argonne, Illinois 60439 USA
}

\begin{abstract}
Liquid metals are attractive candidates for both near-term and long-term fusion applications. The subjects of this comparison are the differences between the two candidate liquid metal breeder materials $\mathrm{Li}$ and $\mathrm{LiPb}$ for use in breeding blankets in the areas of neutronics, magnetohydrodynamics, tritium control, compatibility with structural materials, heat extraction system, safety, and required R\&D program. Both candidates appear to be promising for use in self-cooled breeding blankets which have inherent simplicity with the liquid metal serving as both breeders and coolant. The remaining feasibility question for both breeder materials is the electrical insulation between liquid metal and duct walls. Different ceramic coatings are required for the two breeders, and their crucial issues, namely self-healing of insulator cracks and radiation induced electrical degradation are not yet demonstrated. Each liquid metal breeder has advantages and concerns associated with it, and further development is needed to resolve these concerns.
\end{abstract}

* Work sponsored by the U.S. Department of Energy, Office of Fusion Energy, under Contract Number W-31-109-Eng-38 and by the European Union within the European Fusion Technology Program. 


\section{Introduction}

Liquid metal blankets exhibit many features that make them attractive candidates for both near-term and long-term fusion applications. These advantages include:

1. Immunity to radiation damage. As liquids there are no concerns related to radiation damage lifetime.

2. Potential for tritium self-sufficiency without a beryllium neutron multiplier. Beryllium is an expensive material and the resources are limited. The elimination of beryllium also simplifies the design options and there are no concerns with Be compatibility and radiation damage limits.

3. Tritium extraction outside blanket. Since a liquid can be circulated, it is not necessary to remove the tritium in-situ. This feature allows for greater flexibility for tritium removal options and separates the tritium removal system from the severe environment of the in-vessel components.

4. Low pressure operation. Liquid metal self-cooled systems can potentially operated at high temperatures for greater energy conversion efficiency while at low pressure due to the high boiling point of liquid metal candidates. Low pressure operation is a safety advantage, and in the case of a coolant leak, there are no concerns about over-pressurization of the vacuum vessel as there would be with water cooling.

The liquid metals can serve either as breeder only cooled by helium or water or as breeder and coolant at the same time, circulated relatively fast to the external heat 
exchanger for heat removal. The candidate coolant/breeders are pure $\mathrm{Li}$ and $\mathrm{Pb}$ 1/Li eutectic. Systems without water, i.e. helium- or self-cooled blankets, offer a choice between pure lithium and the eutectic lead-lithium alloy $\mathrm{Pb}-17 \mathrm{Li}$ as breeder/coolant. Water-cooling is possible in lead-lithium blankets only because the high chemical reactivity of lithium with water would cause additional safety concerns. Self-cooled systems have inherent simplicity resulting in a reduced number of tubes compared with a separately cooled system and therefore offer the possibility of increased reliability. Each of the two candidate breeder materials has it is advantages and disadvantages in different areas which makes the selection between them a difficult task.

The main goal of liquid metal blanket design is to make the best use of the attractive features while minimizing the effects of unattractive features. The blanket designs must integrate the performance of the structural materials and other blanket materials (e.g. plasma facing materials, shielding materials, etc.) with the liquid metal performance to achieve an attractive and reliable system. The designs will vary depending on the overall selection of materials and the performance goals of fusion reactor in question. It is not the intent of this paper to address specific designs, but rather to address key areas related to liquid metals alone. An attempt is made here to assess the two candidate liquid metal breeders, taking into account their differences in the fields of neutronics, magnetohydrodynamics, tritium control, compatibility with structural materials, heat extraction system, safety, and required $R \& D$ work. By necessity, the items addressed in the paper are more qualitative than quantitative in nature, since a more quantitative assessment requires complete blanket designs that are compared to the performance goals of a particular fusion device. 


\section{Selected Areas for a Comparison}

A comparison of the physical properties of $\mathrm{Li}$ and $\mathrm{Pb}-\mathrm{Li}$ is given in Table 1. The intention of this paper is to include all relevant issues. No attempt is made to arrive at a quantitative overall ranking but the goal is to identify the most crucial differences.

\subsection{Neutronics}

There are three issues to be compared:

- tritium breeding ratio

- distribution of volumetric heat source,

- shielding properties.

The mechanism influencing the tritium breeding are different for the two materials. The large lead content in $\mathrm{Pb}-17 \mathrm{Li}(99.3 \mathrm{wt} \%$ ) results in an effective neutron multiplication by the $\mathrm{Pb}(\mathrm{n}, 2 \mathrm{n})$-reaction but this is partly compensated for by the higher ${ }^{7} \mathrm{Li}\left(\mathrm{n}, \mathrm{n}^{\prime}\right) \mathrm{t}$ reaction in lithium. $\mathrm{Pb}-17 \mathrm{Li}$ requires enriched $\mathrm{Li}$ to achieve a breeding ratio above unity. Overall, the breeding ratio achievable with $\mathrm{Pb}-17 \mathrm{Li}$ with $\mathrm{Li}$ enriched to $90 \%{ }^{6} \mathrm{Li}$ is slightly higher than the one in natural lithium $\left(7.5 \%{ }^{6} \mathrm{Li}\right)$ and can be equalized by a minor ${ }^{6} \mathrm{Li}$ enrichment in lithium, Malang et al. [1]. The radial power profile is steeper in $\mathrm{Pb}-17 \mathrm{Li}$ and results together with the lower heat conductivity in a steeper temperature profile. $\mathrm{Pb}$ $17 \mathrm{Li}$ has a slight advantage in regard to the shielding properties but this can be compensated for by a few additional $\mathrm{cm}$ of shield in a lithium blanket.

\subsection{Magnetohydrodynamics (MHD)}

The main issues of a comparison are pressure drop, heat transfer and the feasibility of insulating coatings. 


\subsubsection{MHD pressure drop}

Electric currents are induced in liquid metals flowing perpendicular to the tokamak magnetic field, resulting in altered flow patterns and in an additional pressure drop. Liquid metal cooled blankets in high magnetic fields are feasible only if the flowing liquid metal is electrically decoupled from the load carrying walls in order to avoid a short circuit with large currents through the thick walls. This can be achieved by either an insulating coating on the duct walls or by using so called flow channel inserts, Malang et al. [2], where a thin conducting liner only is in contact with the liquid metal. The latter method is limited to tokamaks with a magnetic field strength below $8 \mathrm{~T}$ and a average neutron wall loading below $3 \mathrm{MW} / \mathrm{m}^{2}$. Above these limits either the MHD pressure drop would be to high or too thin a liner would be required.

a) Thin conducting walls

The total pressure drop is dominated in this case by the long poloidal ducts where the flow is perpendicular to the magnetic field and the conducting walls lead to a large current flow. The resulting pressure drop in a rectangular duct can be approximated by the equation, Barleon [3]

$$
\Delta p=v \cdot L \cdot B^{2} \cdot \sigma_{w} \cdot \frac{t_{w}}{a}
$$

with $\mathrm{v}=\mathrm{B}$ liquid metal velocity

$$
\begin{aligned}
& \mathrm{B} \quad=\text { magnetic field strength } \\
& \sigma_{\mathrm{W}} \quad=\text { electrical conductivity of the wall } \\
& \mathrm{a} \quad=\text { channel half width in the direction of B } \\
& \mathrm{L} \quad=\text { channel length. }
\end{aligned}
$$


Equation (1) shows that the MHD pressure drop for given velocity and channel dimensions does not depend on liquid metal properties. However, the lead lithium alloy requires in general higher velocities than lithium in order to obtain the same cooling efficiency as a result of the less favorable heat transport properties (see Table 1).

This makes the pressure drop in $\mathrm{Pb}-17 \mathrm{Li}$ cooled blankets slightly higher than in lithium cooled ones if the differences in heat transfer at the first wall are not considered (see Section 2.2.2)

b) Electrically insulating coatings on duct walls

In insulated ducts with constant cross section and constant magnetic field the induced potential difference is short-circuited only by very thin boundary layers. Therefore, the pressure drop in the long poloidal ducts can be estimated by the equation, Hoffman et al. [4].

$\Delta p=v \cdot B \cdot L \cdot \sqrt{\sigma \cdot \eta / a}$

The product electrical conductivity $\sigma$ and the viscosity $\eta$ is slightly larger for lithium. Larger differences are caused by three-dimensional flowing currents in regions where the velocity, the flow direction or the magnetic field changes. These 3-D-currents can cause a rather large fraction of the total pressure drop in ducts with insulated walls and depend on the electrical conductivity of the liquid metal which is roughly four times as large in lithium compared to $\mathrm{Pb}-17 \mathrm{Li}$. The total pressure drop in insulated 
ducts, however, is orders of magnitudes lower than in ducts with conducting walls.

Altogether, it can be concluded that the differences in pressure drop between the two breeder materials are rather small for identical geometries and velocities. Larger differences may result from the different heat transfer properties as explained in the following section.

\subsubsection{MHD heat transfer}

The crucial issue in designing a self-cooled blanket is the cooling of the first wall. For stress and compatibility reasons the temperature of this wall has to be maintained below given limits, requiring effective heat transfer to the liquid metal. This heat transfer is determined by the velocity, the turbulence and the thermal properties of the liquid metal. For a long time it has been assumed that the strong magnetic field in a blanket suppresses all turbulent motions in the liquid metal. If this is the case, lithium has an important advantage over $\mathrm{Pb}-17 \mathrm{Li}$ due to the much better thermal properties. The difference between the maximum surface temperature of a cooled duct and the inlet temperature of the coolant can be approximated by the equation (see Carlslaw et al. [5])

$$
\Delta \mathrm{T}_{\mathrm{w}}=2 \cdot \mathrm{q}\left(\frac{\mathrm{L}}{\pi \cdot \mathrm{v} \cdot \mathrm{k} \cdot \rho \cdot \mathrm{c}_{\mathrm{p}}}\right)^{1 / 2}
$$

$$
\text { with } \begin{aligned}
\mathrm{q} & =\text { surface heat flux } \\
\mathrm{L} & =\text { duct length } \\
\mathrm{v} & =\text { velocity } \\
\mathrm{k}, \rho, \mathrm{c}_{\mathrm{p}} & =\text { thermal properties (see Table } 1 \text { ). }
\end{aligned}
$$


To obtain the same system $\Delta \mathrm{T}$ with the two breeder materials, $\mathrm{Pb}-17 \mathrm{Li}$ has to flow four times as fast than lithium, taking the values of Table 1 . With the same velocity, the alloy could cool only half the surface heat flux. Thus, the ability to accommodate high power density, particularly at the first wall, is a more serious issue with the $\mathrm{Pb}-\mathrm{Li}$ alloy.

There are indications, however, that the assumption of no turbulence may not be justified for all conditions. Reed et al. [6] have shown that the heat transfer coefficient between a heated wall parallel to the magnetic field and the liquid metal flowing perpendicular to the magnetic field may assume values at least as high as in a turbulent flow without magnetic field. There are indications that a special kind of turbulence ("two dimensional turbulence") occurs in MHD flow characterized by a low interaction parameter $N . N$ is the ratio between electromagnetic force and inertia force and is described by the equation

$$
N=a \cdot \sigma \cdot B^{2} /(\rho \cdot v)
$$

The ratio is for lithium roughly two orders of magnitude larger than for the leadlithium alloy. An enhancement of the heat transfer by this special kind of turbulence is therefore more likely in $\mathrm{Pb}-17 \mathrm{Li}$ than in lithium. This effect may outweigh the lower thermal conductivity of the alloy, but it remains to be seen if this enhancement occurs at all critical locations in a blanket or if there are regions where the heat transfer is still dominated by heat conduction. In the latter case, lithium would have a decisive advantage in the heat transfer area.

\subsubsection{Feasibility of insulating coatings}


It has been shown in Section 2.2.1 that self-cooled blankets in tokamaks with high magnetic fields or high power densities require electrically insulating coatings at the duct walls. The requirements for these coatings are, Malang et al. [7]:

- Compatible with the liquid breeder and the structural material at the maximum blanket temperature.

- In situ formation of a new insulating layer in case of cracks or spallations ("self healing").

- Sufficiently high electrical resistance between liquid metal and blanket structure maintained during irradiation.

The chemical behavior of the eutectic lead-lithium is close to the one of lead and much different from the one of lithium, Borgstedt et al. [8].

This implies that different ceramic coatings are required for the two breeder materials. There are several candidates coatings for $\mathrm{Li}$ and $\mathrm{LiPb}$, but the most near-term promising approach for both materials is to have an aluminum rich sublayer between the insulator and the structural material. This sublayer has to be partly converted to aluminum oxide for application in $\mathrm{Pb}-17 \mathrm{Li}$ and to aluminum nitride for use in lithium. A crack in the insulating layer will expose the sub layer to the liquid metal, allowing oxygen ( $\mathrm{Pb}-17 \mathrm{Li})$ or nitrogen (lithium) to diffuse into the Al-layer and to form locally a new insulator. Both systems have the potential for such a self-healing, but the kinetics has not yet been determined under relevant conditions. The largest uncertainty in the feasibility of insulating coatings, however, is the degradation of the electrical resistance under irradiation, Zinkle et al. [9]. This degradation might be especially severe for this 
application with applied electrical field during irradiation. Unfortunately, the Radiation Induced Electrical Degradation (RIED) has not yet been investigated for relevant fluences or for the proposed coatings. There are no data available for aluminum-nitride and for aluminum-oxide only up to $0.1 \mathrm{dpa}$. There are no data on either material in the form of a thin-coating. It remains to be seen if the remaining resistivity is high enough and if the degradation of the nitride is smaller than the one of the oxide in order to compensate the lower value for the unirradiated nitride (roughly 3 orders of magnitude lower). Fortunately, the required resistivity of the coatings is rather low. An estimate showed, Malang et al. [7] that a value of $10^{3} \mathrm{Ohm} \cdot \mathrm{m}$ would be sufficient for an insulator coating thickness of $10 \mu \mathrm{m}$. Pure unirradiated alumina for example has a resistivity of at least $10^{9} \mathrm{Ohm} \cdot \mathrm{m}$ at $400^{\circ} \mathrm{C}$.

\subsection{Tritium Control}

The crucial issue in case of lithium is tritium inventory, in case of leadlithium the permeation losses to the coolant and the surroundings. An attractive method of tritium removal for self-cooled $\mathrm{Pb}-17 \mathrm{Li}$ blankets has been proposed in Reimann et al. [10]. It is based on the use of a secondary liquid metal with a high solubility of tritium. Sodium-potassium is proposed for this purpose, flowing slowly in the concentric gap of double-walled steam-generator tubes. Tritium permeates from the breeder material through the outer wall into the $\mathrm{NaK}$ where it is recovered by cold trapping. Estimates based on experiments with NaK-cold traps showed, Malang et al. [11] th:

- a tritium partial pressure of $15 \mathrm{~Pa}$ can be maintained,

- the tritium partial pressure in $\mathrm{NaK}$ can be kept at about $10^{-5} \mathrm{~Pa}$ 
- batchwise tritium loading/recovery of the cold-traps is possible with cycling times below one day.

Considering these values it can be stated that tritium recovery is not any more a feasibility issue for $\mathrm{Pb}-17 \mathrm{Li}$. Tritium permeation from the $\mathrm{Pb}-\mathrm{Li}$ alloy is a significant issue in the separately cooled approach, and development of suitable permeation barriers is required.

The development of tritium removal methods from lithium is not advanced to the same level. The requirement is that the tritium concentration in lithium has to be limited to about 1 appm in order to maintain the vulnerable tritium inventory to acceptable levels. There are still a number of removal methods under consideration, Moriyama et al. [12] including molten salt extraction and coldtrapping with isotopic swamping. These methods are possible in principle but have not yet been demonstrated beyond a laboratory scale.

A promising method for tritium removal from lithium based on the cold trap method has recent'y been proposed, Sze et al. [13]. The cold trap method can only reduce the hydrogen concentration to about $400 \mathrm{appm}$, far above the goal of $\sim 1$ appm. To achieve this lower goal, protium is added to the lithium to a concentration higher than the saturation concentration at the cold trap temperature $\left(\sim 200^{\circ} \mathrm{C}\right)$. Thus both $\mathrm{LiH}$ and $\mathrm{LiT}$ will precipitate at the cold trap. The tritium can then be recovered by heating the $\mathrm{Li}(\mathrm{H}+\mathrm{T})$ to $600^{\circ} \mathrm{C}$ for decomposition, and the $T$ can then be separated by a cryogenic distillation process. Experimental work is needed to demonstrate this process.

\subsection{Compatibility with Structural Materials}


Candidate structural materials for self-cooled blankets are ferritic steels and vanadium alloys. Lithium exhibits better compatibility with both structural materials, Moriyama et al. [12], Chopra et al. [14], Borgstedt et al. [15,17], Chopra et al. [16]. However, the lower allowable interface temperature of both structural materials in contact with lead-lithium does in general not limit the blanket performance, especially if there is an insulating coating on the duct walls. But even in the case of ferritic steel in contact with $\mathrm{Pb}-17 \mathrm{Li}$ the allowable temperature level is limited by mechanical stresses rather than by the corrosion rate, Malang et al. [11].

However, in the case of vanadium alloys, there is a difference in regard to impurities in the liquid metal breeder. The excellent gettering properties of lithium for oxygen and hydrogen limit the partial pressure of these impurities to very low values, resulting in low concentrations of oxygen and hydrogen in the structural material.

\subsection{Heat Extraction System}

An important advantage of self-cooled blankets is the arrangement of the large heat transfer surface outside the torus because there is no irradiation environment and it is possible to provide redundancy. In all other blanket concepts there are some kilometers of small tubes with a large number of welds required in order to transfer the heat from the breeder to the coolant. Self-cooled blankets therefore have an advantage with regard to reliability and, combined with the shorter repair time for failed components, a higher availability. The drawback are large liquid metal loops transporting heat and tritium from the blankets to the steam generators and tritium removal systems respectively. The components to be compared for the two liquid metal breeder materials are: 
- steam generator,

- tritium removal system,

- circulation pumps.

The differences in the tritium removal system have been discussed already in Section 2.3. It has been shown there that the system proposed for lead-lithium self-cooled blankets requires only one liquid metal system to transport the heat from the blankets to the steam cycle. This is not possible for lithium self-cooled blankets because the higher chemical reactivity of this liquid metal requires a secondary heat transport loop in order to separate completely the lithium from the steam cycle. There are a number of coolants for this secondary system under discussion, including organic coolants and other liquid metals, Smith et al. [18]. Furthermore, it is very likely that an inert gas environment will be required for the entire lithium system. With regard to the circulation pumps a distinction has be made between electromagnetic and rotary pumps. The higher electrical conductivity of lithium results in a higher efficiency of electromagnetic pumps if they can be developed for the high flow rates and pressure drops of self-cooled blankets. Large EM pumps have been used for existing liquid metal reactors, and the technology should be applicable to fusion systems. One-stage rotary pumps are available for the conditions of self-cooled lead-lithium blankets but more complicated multi-stage pumps may be required for lithium due to the low density.

All together it can be concluded that the heat extraction system for $\mathrm{Pb}$ 17 $\mathrm{Li}$ does not require a secondary heat exchanger and therefore is less complex 
than the one for lithium. However, as noted in Section 2.3, a double wall heat exchanger with $\mathrm{NaK}$ flowing in the annulus is to be used for the $\mathrm{Pb}-\mathrm{Li}$ alloy.

\subsection{Safety}

The issues related to safety for the two liquid metals include the chemical reactivity of the liquid breeder and the generation of radioactive products, Malang et al. [19].

\subsubsection{Chemical reactivity of the liquid metal breeders}

Lithium reacts vigorously with water, air, concrete, carbon dioxide and nitrogen, Barnet et al. [20], Piet et al. [21]. Usually, these reactions go on until there is no lithium left. Temperatures in excess of $1000^{\circ} \mathrm{C}$ can be reached, leading to a high mobility of activated products. The reactivity of $\mathrm{Pb}-17 \mathrm{Li}$ is much less. It reacts significantly with water, carbon dioxide, and the water content of concrete but has very mild reactions with air and nitrogen, Jeppson et al. [212], Kranert et al. [23]. The maximum temperature which can be reached by chemical reaction is much lower for the alloy than for lithium because the lithium content per volume is roughly $1 / 6$ compared to pure lithium. Another important difference between the two liquid metals is the liberation of hydrogen in a reaction with water if this reaction can not be completely avoided. In the case of the alloy, most of the hydrogen from the water reacted is released. In the case of lithium, however, most of the hydrogen is bound to the liquid metal as $\mathrm{LiH}$ until the temperature level exceeds $1000^{\circ} \mathrm{C}$ and the hydride is decomposed. Hydrogen liberation is of special concern in the case of an air environment because an explosive mixture of the two gases has to be avoided in any case. 
For these reasons it is obvious that lithium cooling is feasible only if a contact between this liquid metal and water is made extremely unlikely be design measures. The preferred method is to avoid water-cooled components in the vicinity of lithium loops. But even if a lithium-water reaction is made impossible, the high chemical reactivity of this liquid metal with some gases could lead to high temperatures and consequently to the release of radioactıve impurities. Therefore, proposed designs with lithium use an inert gas atmosphere. This is not likely to be required for $\mathrm{Pb}-17 \mathrm{Li}$ systems although an inert :ower gas may still be desirable. It can be concluded that the use of lithium in self-cooled blankets requires additional measures for chemical reactivity to achieve the same safety level as achievable with $\mathrm{Pb}-17 \mathrm{Li}$.

\subsubsection{Activation products in the liquid metal breeder}

Tritium activity accounts for the largest fraction of the total radioactivity in liquid metal breeders. This points to the fact that effective extraction methods are required to limit tritium concentration (see Section 2.3). Other important sources for radioactivity in the liquid metal breeders are corrosion products from the blanket structural material and, in the case of $\mathrm{Pb}-17 \mathrm{Li}$, the lead itself together with impurities such a bismuth, polonium, thallium and mercury.

Of special concern in $\mathrm{Pb}-17 \mathrm{Li}$ blankets is the $\alpha$-emitter polonium-210, Hoffman et al. [24]. This impurity is formed from bismuth by neutron activation. Bismuth is either an original impurity of lead or build up from lead during the irradiation. Experiments have shown, Feuerstein [25], that the release of polonium is determined by the vapor pressure of an intermetallic $\mathrm{Po}-\mathrm{Pb}$ compound which is orders of magnitude lower than that one of polonium which has been assumed in previous release studies. Therefore, the release of Po-210 is 
not as critical as described in a number of publications in the past. Nevertheless, it is desirable to develop one-line Bi-removal to a level of $1 \mathrm{ppm}$, resulting in approximately $0.1 \mathrm{ppb}$ Po-210 without any polonium removal.

The total content of radioactive impurities without tritium in lithium is much smaller than in $\mathrm{Pb}-17 \mathrm{Li}$. This makes the potential for a radioactivity release smaller if chemical reactions leading to higher temperatures can be avoided. The only way to ensure this with a higi, confidence is probably in inert gas environment for all lithium containing components.

\subsection{Specific Design Issues}

The high density of the lead lithium alloy results in an additional static liquid metal pressure in the blanket segment of up to $2 \mathrm{MPa}$. This requires a stronger first wall in order to limit mechanical stresses. It is design dependent if this is a relevant disadvantage or if the strength of the first wall is determined by the forces caused by plasma disruptions. Liquid metal spills into the plasma chamber are more difficult to clean up in the case of the alloy because a solvent (acetic acid) may be needed and remaining traces of lead would be more damaging to the plasma performance.

\subsection{Required R\&D Work}

The R\&D work required for self-cooled liquid metal blankets can be subdivided into the following levels:

a) Solution of feasibility issues for each of the two liquid metal breeder concepts. 
b) Evaluation of issues with a significant impact on the relative attractiveness.

c) Engineering development and optimization of particular concept.

For the present comparison only the level a) shall be discussed because these questions have to be answered before one of the two liquid breeders can be selected.

The most important feasibility issue of self-cooled blankets is the electrical insulation of the liquid metal channels. The most attractive solution are ceramic coatings in contact with the liquid metal with the crucial issues

- $\quad$ self-healing

- degradation by irradiation

More work is necessary to investigate these issues for the two candidate insulator materials.

A key issue of lithium blankets is the tritium extraction. From the candidate methods under discussion the most promising one has to be selected and its performance needs to be demonstrated.

Typical for the use of $\mathrm{Pb}-17 \mathrm{Li}$ as fiist wall coolant is the requirement of enhanced heat transfer by turbulent motions. Simple poloidal coolant channels in a power reactor are not possible without such an enhancement if $\mathrm{Pb}-17 \mathrm{Li}$ is used. It remains to be seen, if such an enhancement can be assured at all critical locations in a $\mathrm{Pb}-17 \mathrm{Li}$ cooled blanket. This requires MHD-experiments as well as 
new theoretical models describing velocity profiles and turbulence in insulated ducts.

Chemical reactivity is a more critical issue for lithium blankets, and suitable methods for controlling reactivity need to be used (e.g. inert atmosphere). The alloy, however, requires additional work to develop suitable purification methods to reduce the level of activation products.

\section{Conclusion}

Liquid metals have the potential advantages of immunity to radiation damage, the potential for tritium self-sufficiency without a beryllium neutron multiplier, the possibility of tritium extraction outside the blanket low-pressure and high temperature operation, and attractive heat transfer and heat removal characteristics. Both pure $\mathrm{Li}$ and $\mathrm{Pb}$ - $\mathrm{Li}$ have attractive features as well as concerns. In most cases, design solutions have been identified to address these concerns, and R\&D is being performed to address key issues. The outstanding issue to be resolved is the feasibility of insulating coatings on the duct walls needed to maintain a low MHD pressure drop. There are different ceramic coatings required and under development for the two liquid metals, and work should continue on the leading candidate insulators until the feasibility issues are solved. 


\section{References}

[1] S. Malang, K. Arheidt and U. Fischer. Test Module in NET for a Selfcooled Liquid-metal Blanket Concept. Proc. 15th Symp. on Fusion Technol. Utrecht, The Netherlands. September 1988. Vol. 2, ed. A. M. van Ingen (Elsevier Sc. Pub., Amsterdam, 1989) pp. 1223 - 1228.

[2] S. Malang, U. Casal, K. Arheidt, U. Fischer, W. Link, K. Rust. Liquid Metal Cooled Blanket for NET. Proc. 14 Symp. on Fusion Technol. Avignon, France. September 1984, Vol. 2, (Pergamon Press, Oxford) pp. $1273-1278$.

[3] L. Barleon, U. Casal, L. Lenhart. MHD Flow in liquid metal cooled blankets. Fus. Eng. and Design 14 (1991) $401-412$.

[4] M.A. Hoffman, G.A. Carlson. Calculation Techniques for Estimating the Pressure Losses for Conducting Fluid Flows in Magnetic Fields. Lawrence Livermor Laboratory. UCRL-51010 (1971).

[5] H.S. Carlslaw, I.C. Jaeger. Conduction of heat in solids, 2nd ed (Clarendon Press. Oxford, 1959).

[6] C.B. Reed, T.Q. Hua, D.B. Black, I.R. Kirillov, S.I. Sidorenkov, A.M. Shapiro, I.A. Evtushenko. Liquid Metal MHD and Heat Transfer in a Tokamak Blanket Slotted Coolant Channel. IEEE/NPSS-Fusion 15th Symp. on Fusion Engineering. Hyannis, MA. October 12-15, 1993. 
[7] S. Malang, H.U. Borgstedt, E.H. Farnum, K. Natesan, I.V. Vitkovski. Development of Insulating Coatings for Liquid Metal Blankets. This Conference.

[8] H.U. Borgstedt. Chemische Eigenschaften des fluessigen Blanketstoffs $\mathrm{Pb}$ 17Li. Kernforschungszentrum Karlsruhe. KfK-4620 (Aug. 1989).

[9] S.I. Zinkle, E.R. Hodgson. Radiation-induced changes in the physical properties of ceramic materials. Journal of Nuclear Materials 191-194 (1992) 58-66.

[10] J. Reimann and S. Malang. A Study of tritium separation from LiPb by permeation into $\mathrm{Na}$ or $\mathrm{NaK}$ and cold trapping. Kernforschungszentrum Karlsruhe. KfK-4105 (Oct. 1986).

[11] S. Malang, J. Reimann, H. Sebening (ed). DEMO-relevant Test blanket for NET/ITER. Part 1: Self-cooled Liquid Metal Breeder Blanket, Vol. 1: Summary. Kernforschungszentrum Karlsruhe. KfK-4907 (Dec. 1991).

[12] H. Moriyama, S. Tanaka, D.K. Sze, J. Reimann, A. Terlain. Tritium Recovery from Liquid Metals. This conference.

[13] D. Sze, R. Mattas, J. Anderson, R. Haange, H. Yoshida, and O. Kveton. Tritium Recovery from Lithium Based on Cold Trap. This conference.

[14] O.K. Chopra, D.L. Smith. Corrosion behavior of vanadium alloys in flowing lithium. J. Nucl. Mater. 155 - 157 (1988) 683-689. 
[15] H.U. Borgstedt, M. Grundmann, J. Konys, S. Peric. A vanadium alloy for the application in a liquid metal blanket of a fusion reactor. J. Nucl. Mater. $155-157$ (1988) 690-693.

[16] O.K. Chopra, D.L. Smith. Compatibility of ferritic steels in forced circulation lithium and Pb-17Li systems. J. Nucl. Mater. 155-157 (1988) 715-721.

[17] H.U. Borgstedt, H.D. Roehrig. Recent results on corrosion behavior of manet structural steel in flowing $\mathrm{Pb}-17 \mathrm{Li}$ eutectic. J. Nucl. Mater. 176 (1990).

[18] D.L. Smith et al. Blanket Comparison and Selection Study (Final Report). Argonne National Laboratory. ANL/FPP-84-1, Vols. 1, 2 and 3 (Sept. 1984).

[19] S. Malang, P. Leroy, G.P. Casini, R.F. Mattas, Yu. Strebkov. Crucial issues on liquid metal blanket design. Fusion Eng. and Design 16 (1991) 95-109.

[20] D.S. Barnet, M.S. Kazimi. The consequences of lithium fires in the presence of steam. Fusion Technol. 15 (1989) 839-846.

[21] S.J. Piet, D.W. Jeppson, L.D. Muehlestein, M.S. Kazimi. Liquid metal chemical reaction safety in fusion facilities. Fusion Engrg. Des. 5 (1987) 273-298. 
[22] D.W. Jeppson, L.D. Muehlestein. Safety consideration of Lithium Lead Alloy as a Fusion Reactor Breeding Material. Fus. Techn. 8 (1985) 138591.

[23] O. Kranert, H. Kottowski, C. Savatteri, M. Corradini. Large scale liquid metal-water interaction studiies. Proc. Fourth International Topical Meeting on Nuclear Reactor Thermal Hydraulics (NURETH-4). Karlsruhe, Oct. 1013, 1989. Vol. 2, 890-895.

[24] N. Hoffman, K.A. Murray, I.A. Blink, W.R. Meier, W.F. Vogelsang. Polonium aspects associated with the use of lead-lithium blankets in fusion applications. Fus. Techn. 8 (1985) 1376-84.

[25] H. Feuerstein, I. Oschinsky. Behavior of Po-210 in molten $\mathrm{Pb}-17 \mathrm{Li}$. 5th Int. Conf. on Fusion Reactor Materials. Clearwater, Florida, USA. Nov. 17-22, 1991 . 
Table 1. Physical Properties of $\mathrm{Li}$ and $\mathrm{Li}_{17} \mathrm{~Pb}_{83}\left(300^{\circ} \mathrm{C}\right)$

\begin{tabular}{lcc}
\hline \multicolumn{1}{c}{ Property } & $\mathrm{Li}$ & $\mathrm{Li}_{17} \mathrm{~Pb}_{83}$ \\
\hline Melting Point (C) & 181 & 235 \\
Boiling Temperature (C) & 1317 & -- \\
Density $\left(\mathrm{kg} / \mathrm{m}^{3}\right)$ & 505 & 9500 \\
Latent Heat & & \\
Fusion kJ/kg & 66.2 & -- \\
Vaporization & 19,595 & 3.5 \\
Volume Expansion on Melting $(\%)$ & 1.5 & 13.2 \\
Thermal Conductivity W/mk & 46 & .190 \\
Specific Heat Ws/kgK & 4260 & .188 \\
Viscosity $10^{-6} \mathrm{~m}^{2} / \mathrm{s}$ & .82 & $2.38 \times 10^{-2}$ \\
Prandtl-number & $3.62 \times 10^{-2}$ & .77 \\
Electrical Conductivity $10^{6} \mathrm{~A} / \mathrm{v} \bullet \mathrm{m}$ & 3.03 & \\
\hline
\end{tabular}



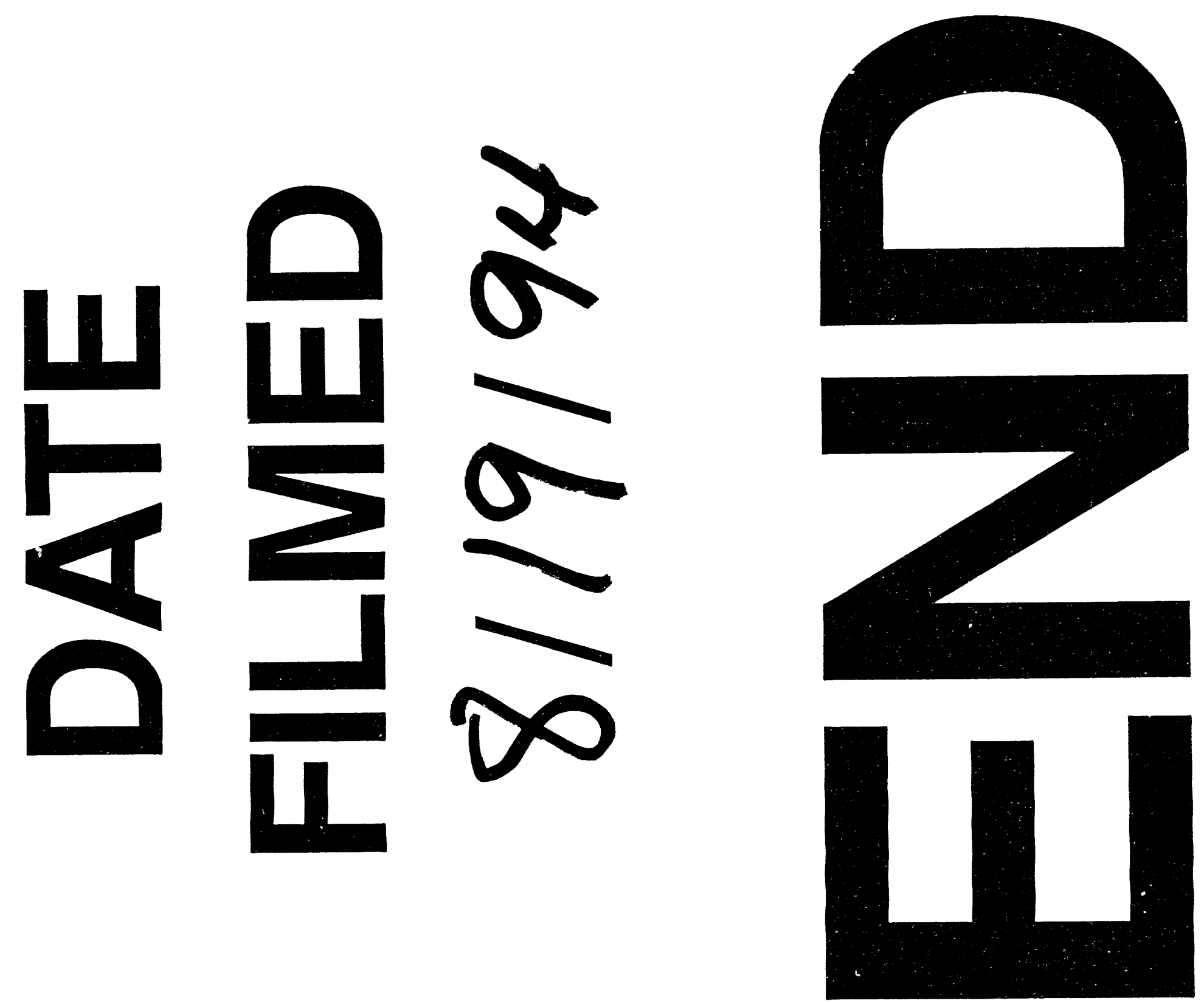